\title{
下肢切断者と健常者の筋収縮特性の違い
}

\section{Differences in Muscle Contraction Characteristics of Lower Limb Amputees and Non-amputees}

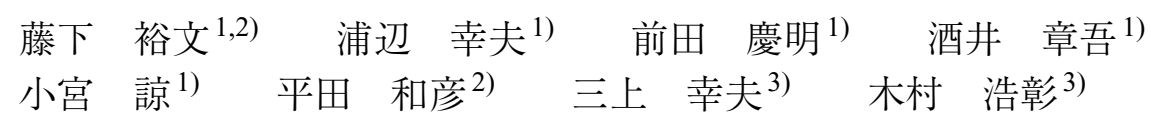

Hironori FUJISHITA, RPT, MSc ${ }^{1,2)}$, YUKIo URABE, RPT, PhD ${ }^{1)}$, Noriaki MAEDA, RPT, PhD ${ }^{1)}$, Shogo SAKAI, RPT, MSc ${ }^{1)}$, Makoto KOMIYA, RPT, MSc ${ }^{1)}$, KazUhiKo HIRATA, RPT ${ }^{2)}$, Yukio MIKAMI, MD, PhD $^{3)}$, Hiroaki KIMURA, MD, PhD ${ }^{3)}$

${ }^{1)}$ Graduated School of Biomedical \& Health Sciences, Hiroshima University: 1-2-3 Kasumi, Minami-ku, Hiroshima-shi, Hiroshima 734-8553, Japan TEL+81 82-257-5405 E-mail: h-fujishita@hiroshima-u.ac.jp

${ }^{2)}$ Sports Medical Center, Hiroshima University Hospital

${ }^{3)}$ Department of Rehabilitation Medicine, Hiroshima University Hospital

Rigakuryoho Kagaku 34(1): 83-87, 2019. Submitted Aug. 6, 2018. Accepted Sep. 21, 2018.

ABSTRACT: [Purpose] The purpose of this study was to investigate the muscle contraction characteristics of lower limb amputees. [Participants and Methods] The participants were 6 lower limb amputees and 7 healthy men. Their muscle contraction characteristics were measured by tensiomyography (TMG). TMG is a non-invasive neuromuscular functional assessment. TMG measurements were made of the contraction time and maximum radial displacement of the gastrocnemius lateralis and medialis, rectus femoris, and vastus lateralis and medialis. [Results] Muscle contraction time of the gastrocnemius was significantly delayed in amputees. [Conclusion] The muscle contraction time of the gastrocnemius muscles was significantly different from that of the non-amputees, suggesting it is a characteristic of amputees.

Key words: tensiomyography, lower limb amputation, muscle contraction property

要旨：〔目的〕本研究の目的は, 下肢切断者の非切断側の筋収縮特性について調査することである.〔対象と方法〕対 象は，運動習慣のある下肢切断者 6 名と健常成人 7 名とした。筋収縮特性測定器（Tensiomyography）を用いて，電 気刺激に対する筋の収縮速度や筋幅の最大変位量の測定を行った。測定部位は, 下肢切断者では非切断側, 健常者は 利き脚とし, 腓腹筋外側頭, 内側頭, 大腿直筋, 外側広筋, 内側広筋の 5 筋とした。〔結果〕下肢切断者では腓腹筋 の収縮時間が健常者よりも有意に遅延した。〔結語〕下肢切断者の非切断側下肢では健常者と筋収縮特性が異なるこ とを示唆した.

キーワード : 筋収縮特性測定器, 下肢切断, 筋収縮特性

1) 広島大学大学院＼cjkstart医歯薬保健学研究科：広島県広島市南区霞 1-2-3 ( ₹ 734-8553) TEL 082-257-5405

2) 広島大学病院 スポーツ医科学センター

3) 広島大学病院 リハビリテーション科 


\section{I.はじめに}

下肢切断者が行うスポーツには，陸上競技やアンプ ティサッカーをはじめ様々な種目がある。 2020 年の東 京オリンピック・パラリンピック開催もあり, スポーツ を行う障がい者が増加している1)。障がい者スポーツの 特徵の一つとして，身体の一部に機能障害があるために それ以外の残存機能を強化して競技を行っている。 下肢 切断者の場合では義足を用いることはあるが，走行能力 など非切断側の機能が競技力にも影響する ${ }^{2)}$ ，その一方 で，残存機能の酷使による傷害も起きやすく, Bernardi らは，運動機能に障がいを有しているアスリートのなか で，下肢切断者のスポーツ関連性筋疼痛の発生頻度が多 いと報告している3)。 また，競技力向上に向けてトレー ニングを行う必要があるが, 効率的なトレーニングを行 うことが求められる。 そのためには選手の特徵を知る必 要があり, 筋収縮の特徴を評価する必要がある.

近年, 機械的筋収縮特性測定器 (Tensiomyography： 以下， TMG）は，非侵襲的に骨格筋の評価を行うこと ができる方法として欧州のスポーツ現場を中心に使用さ れている. TMGは，電気刺激を骨格筋に与えて筋収縮 を誘発させ，筋収縮に伴う筋腹に対し垂直な方向への最 大変位および最大変位に至るまでの時間を記録する機器 である，TMGを用いることで，筋の収縮時間や筋疲労 筋線維タイプ，筋スティフネスを評価することができ， 簡便に筋の状態を知ることが可能である 4 ,5). 筋の収縮 特性を把握することによって，どのようなトレーニング 方法が競技力向上に最適であるかを判断し，質の高いト レーニングの考案につながると考えられる.

しかしながら，TMGを用いた筋収縮特性の測定は健 常者のスポーツで行われているが，障がい者を対象とし た研究は少なく, これまでに下肢切断者の非切断側の筋 収縮特性について報告した研究はない.

そこで本研究の目的は, 下肢切断者の非切断側の筋収 縮特性について調査することとした。
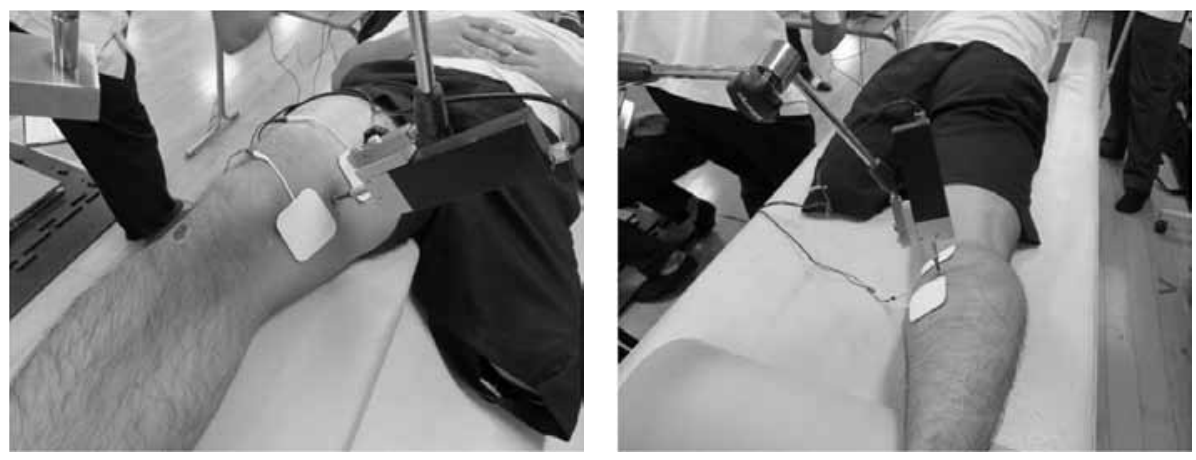

図1 TMGの測定風景

\section{1. 対象}

対象は，定期的な運動習慣のある片側下肢切断を有す る健康な男性 6 名と下肢切断のない健康な男性 7 名とし た。いずれも利き脚または非切断側に整形外科的な疾患 を過去 1 年以上有していない者とした。 下肢切断者は, 義足を装着して一般的な社会生活を送っている者で, 切 断部位の内訳は下腿切断者 2 名, 大腿切断者 4 名であっ た。切断原因に関しては，交通事故 3 名，労災事故 2 名 骨肉腫 1 名であった，対象者が主に参加している競技は, アンプテイサッカー 4 名, 陸上競技 1 名, 野球 1 名であっ た。 また，非切断側に整形外科的な疾患を有している者， 末梢循環障害に起因した切断者および同意が得られない 者は対象から除外した。

対象には事前に研究の趣旨および方法を書面および口 頭にて十分に説明し，同意を得て実施した。本研究は， 広島大学病院臨床研究倫理審査委員会の承認を得て実施 した（承認番号：C-197）。

2. 方法

TMG は，電気刺激を骨格筋に与えて筋収縮を誘発さ せ，筋収縮に伴う筋腹に対し垂直な方向への变位量およ び最大変位に至るまでの時間を測定する機器である. TMG のセンサーロッドには $0.17 \mathrm{~N} / \mathrm{mm}$ のバネが組み込 まれており，測定する対象筋にセットする際は圧を一定 に保ち圧力の違いによる測定值の変化を防止するために センサーロッドの先端が総変位長の $1 / 2$ となるところま で差し込む。 センサーロッドの設置位置は, Delagiら の報告を参考に設置し，電気刺激用の電極 $(5 \mathrm{~cm} \times 5$ $\mathrm{cm})$ は，センサーロッドを中心に電極間の距離が $5 \mathrm{~cm}$ となるように貼付した6)（図 1)。この際，電極が皮膚 と密着するように必要に応じて剃毛処理を行った。

TMG では，主に以下の指標を用いられ，最大変位 (Maximal Displacement：以下，Dm）は，電気刺激に対 して収縮した筋の垂直方向の変位量を表し，筋スティフ ネスに関係しており，筋組織の柔軟性を反映する。収縮 
表 1 対象者の基本情報

\begin{tabular}{lcc}
\hline & 下肢切断者群 $(\mathrm{n}=6)$ & 健常者群 $(\mathrm{n}=7)$ \\
\hline 年齢 $($ 歳 $)$ & $36.5 \pm 5.4^{*}$ & $23.1 \pm 1.4$ \\
身長 $(\mathrm{cm})$ & $174.8 \pm 8.7$ & $173.0 \pm 8.4$ \\
体重 $(\mathrm{kg})$ & $71.7 \pm 20.9$ & $66.1 \pm 11.1$ \\
Body Mass Index $\left(\mathrm{kg} / \mathrm{m}^{2}\right)$ & $23.2 \pm 5.1$ & $22.0 \pm 2.2$ \\
切断年数 (年) & $16.2 \pm 11.9$ & \\
切断部位 & 大腿切断 4 名 \\
& 下腿切断 2 名 \\
切断原因 & 交通事故 3 名 \\
& 労働災害 2 2 名 \\
& 骨肉腫 1 名 \\
競技種目 & アンプティサッカー 4 名 \\
& 陸上競技 1 名 \\
野球 1 名 \\
\hline
\end{tabular}

平均值 \pm 標準偏差. $*: \mathrm{p}<0.05$.

時間（Contraction Time：以下, Tc）は, Dm の 10\%か ら 90\%に至るまでの時間を表し, 筋線維タイプに関連 する，遅延時間（Delay Time：以下，Td）は，電気刺 激から $\mathrm{Dm}$ の $10 \%$ に至るまでの時間であり, 神経伝達 速度と関係する。これら 3 つの指標については先行研究 で測定の信頼性が報告されている7)。TMG (TMG-BMC 社製）の測定は同一の検查者が実施し，被検筋は腓腹筋 外側頭 (Gastrocnemius Lateralis：以下, GL), 腓腹筋 内側頭 (Gastrocnemius Medialis：以下, GM), 大腿直 筋 (Rectus Femoris : 以下, RF), 外側広筋（Vastus Lateralis：以下, VL), 内側広筋（Vastus Medialis：以下 VM）の 5 筋とした.

さらに，固体内の異なる筋間を比較するために応答ス ピード（Normalized response speed：以下， $V_{\mathrm{rn}}$ ）を算出 した. $\mathrm{V}_{\mathrm{rn}}$ は 10〜90\%の Dmの変化量と $10 \sim 90 \% \mathrm{Dm}$ 間の時間の関係を表して抢り ${ }^{8,9}, \mathrm{~V}_{\mathrm{rn}}=0.8 / \mathrm{t}_{\mathrm{c}}(\mathrm{mm}$. $\left.\mathrm{s}^{-1}\right)$ と計算することができる。

測定は先行研究を参考に, 電気刺激装置（TMG-100） のパルス持続時間を $1 \mathrm{~ms}$ とし, 開始電流を $50 \mathrm{~mA}$ とし たの)。電流を $10 \mathrm{~mA}$ ずつ上げ，出力が最大の $110 \mathrm{~mA}$ に達するか, 得られる波形の変化が皆無もしくは最小に なるまでの繰り返し電気刺激を行った。電気刺激の間隔 は筋の活性化や疲労の影響を排除するために 10 秒間の 間隔をあけた ${ }^{10)}$ 。測定姿位は，腓腹筋の測定では測定 用のベッド上に安静腹臥位にさせ，足関節の部分に付属 の半円柱状の枕を配置した。大腿直筋，外側広筋，内側 広筋の測定時には, ベッド上で安静仰臥位にさせ, 膝下 に付属の三角枕を配置した。

統計解析には, SPSS Ver. 20（日本 IBM 社製）を用い, 正規性の検定として Kolmogorov-Smirnov 検定を行っ た。下肢切断者と健常者の比較には正規性のある場合に, 対応のないt検定, 正規性がない場合にはMann-
表 $2 \mathrm{TMG}$ の各筋の測定結果

\begin{tabular}{llrr}
\hline Muscle & \multicolumn{1}{c}{ TMG } & 下肢切断者群 & \multicolumn{1}{c}{ 健常者群 } \\
\hline $\mathrm{GL}$ & $\mathrm{Tc}(\mathrm{ms})$ & $24.1 \pm 4.7^{*}$ & $20.8 \pm 2.1$ \\
& $\mathrm{Dm}(\mathrm{mm})$ & $4.6 \pm 0.9$ & $4.5 \pm 1.6$ \\
& $\mathrm{Td}(\mathrm{ms})$ & $21.4 \pm 0.8^{*}$ & $20.1 \pm 0.9$ \\
$\mathrm{GM}$ & $\mathrm{Tc}(\mathrm{ms})$ & $27.9 \pm 4.0^{*}$ & $23.0 \pm 1.2$ \\
& $\mathrm{Dm}(\mathrm{mm})$ & $4.9 \pm 1.0$ & $5.0 \pm 1.1$ \\
& $\mathrm{Td}(\mathrm{ms})$ & $24.2 \pm 1.1^{*}$ & $22.0 \pm 1.0$ \\
$\mathrm{RF}$ & $\mathrm{Tc}(\mathrm{ms})$ & $27.8 \pm 3.5$ & $26.4 \pm 2.5$ \\
& $\mathrm{Dm}(\mathrm{mm})$ & $8.6 \pm 2.7 *$ & $11.6 \pm 2.1$ \\
& $\mathrm{Td}(\mathrm{ms})$ & $25.1 \pm 2.3$ & $26.2 \pm 1.8$ \\
$\mathrm{VL}$ & $\mathrm{Tc}(\mathrm{ms})$ & $20.4 \pm 2.6$ & $18.7 \pm 1.5$ \\
& $\mathrm{Dm}(\mathrm{mm})$ & $5.2 \pm 1.7$ & $6.6 \pm 1.7$ \\
& $\mathrm{Td}(\mathrm{ms})$ & $21.1 \pm 1.0$ & $20.9 \pm 0.8$ \\
$\mathrm{VM}$ & $\mathrm{Tc}(\mathrm{ms})$ & $22.9 \pm 2.4$ & $21.5 \pm 1.5$ \\
& $\mathrm{Dm}(\mathrm{mm})$ & $7.5 \pm 2.8$ & $8.2 \pm 1.6$ \\
& $\mathrm{Td}(\mathrm{ms})$ & $21.5 \pm 1.5$ & $21.4 \pm 0.4$ \\
\hline
\end{tabular}

平均値 \pm 標準偏差. $*: p<0.05$. GL : Gastrocnemius Lateralis, GM : Gastrocnemius Medialis, RF : Rectus Femoris, VL : Vastus Lateralis, VM : Vastus Medialis, Tc : Contraction Time, Dm : Maximum Displacement, Td : Delay Time.

Whitney U 検定を実施した。健常者群と下肢切断者群で の各群内に打ける各骨格筋間の比較には 1 元配置分散分 析を行い，事後検定には Holm 法を用いた。いずれも有 意水準は $5 \%$ とした。

\section{III. 結 果}

対象者の基本情報を表 1 に示す，年齢に有意な差を認 め, 下肢切断者で年齢が高かった，TMG で測定した筋 収縮特性の結果を表 2 に示した。腓腹筋外側頭 $(\mathrm{GL})$ 
表 3 応答スピード (Vrn) の結果

\begin{tabular}{lccccc}
\hline & $\mathrm{GL}$ & $\mathrm{GM}$ & $\mathrm{RF}$ & $\mathrm{VL}$ & $\mathrm{VM}$ \\
\hline 下肢切断者群 $\left(\mathrm{mm} \cdot \mathrm{s}^{-1}\right)$ & $34.0 \pm 5.3$ & $29.2 \pm 4.0^{*}$ & $29.2 \pm 3.4$ & $39.8 \pm 5.5$ & $35.3 \pm 3.6$ \\
健常者群 $\left(\mathrm{mm} \cdot \mathrm{s}^{-1}\right)$ & $38.8 \pm 3.9$ & $34.9 \pm 1.8$ & $30.6 \pm 3.1$ & $43.1 \pm 3.6$ & $37.4 \pm 2.6$ \\
\hline
\end{tabular}

平均值 \pm 標準偏差. *: $\mathrm{p}<0.05$. GL : Gastrocnemius Lateralis, GM : Gastrocnemius Medialis,

RF : Rectus Femoris, VL : Vastus Lateralis, VM : Vastus Medialis.

と腓腹筋内側頭 $(\mathrm{GM})$ の収縮時間（Tc）および遅延時 間（Td）では，下肢切断者が健常者より有意に高值を 示した $(\mathrm{p}<0.05)$. 大腿直筋 $(\mathrm{RF})$ の最大变位 $(\mathrm{Dm})$ は, 下肢切断者が健常者より有意に低值であった（ $\mathrm{p}<$ 0.05). その他の筋に関しても有意な差はなかったが, 切断者では健常者に比べ収縮時間（Tc）や遅延時間 （Td）が小さい傾向を示した.

下肢切断者と健常者の応答スピード（Vrn）の結果を 表 3 に示す。健常者では大腿直筋 $(\mathrm{RF})$, 腓腹筋内側頭 $(\mathrm{GM})$, 内側広筋 $(\mathrm{VM})$, 腓腹筋外側頭 $(\mathrm{GL})$, 外側広 筋（VL）の順に高值を示し, 外側広筋 $(\mathrm{VL})$ が最も応 答スピードが大きい傾向を示した。一方で下肢切断者は， 大腿直筋 $(\mathrm{RF})$, 腓腹筋内側頭 $(\mathrm{GM})$, 腓腹筋外側頭 $(\mathrm{GL})$, 内側広筋 $(\mathrm{VM})$, 外側広筋 $(\mathrm{VL})$ という順に高 值を示し, 切断者も外側広筋 $(\mathrm{VL})$ の応答スピードが 大きい結果となった。 また，下肢切断者と健常者を比較 すると, 腓腹筋内側頭 $(\mathrm{GM})$ の応答スピードが下肢切 断者では有意に小さかった $(\mathrm{p}<0.05)$.

\section{IV. 考 察}

本研究は, TMG を用いて下肢切断者を対象とした初 めての試みである。最も注目すべき結果は, 下肢切断者 の腓腹筋外側頭 (GL) および内側頭 $(\mathrm{GM})$ で筇収縮 の反応が，健常者と比較して遅延していたことである。 筋の収縮速度を反映する収縮時間（Tc）や遅延時間 （Td）の遅延は，筋線維の収縮特性の違いが影響してい る可能性が考えられる. 筋線維には大きく分けて 2 種類 の線維タイプが存在し, Type I 線維は, 収縮速度は遅 いが笳持久力に優れており, Type II 線維は, 早く強く 収縮するが疲れやすいという性質を持っている。 TMG の収縮時間（Tc）は筋線維タイプの占める割合と関連 していることが報告されており ${ }^{11)}$ ，TMGを用いて長距 離走などの持久力系競技者と跳躍などのパワー系競技者 の筋収縮反応を比較した先行研究では，持久系競技者の 方が収縮時間（Tc）や遅延時間（Td）が遅延してい た ${ }^{12)}$. したがって，片側下肢切断者でスポーツを行っ ている人の腓腹筋では, Type I 線維の割合いが多い可 能性がある。

下肢切断者と健常者で腓腹筋の筋収縮の反応が異なっ た要因について，下肢切断者では日常的な非切断側への
負荷が大きいことが考えられる．下肢切断者は普段の生 活や社会活動を行ううえで，義足を装着して歩行や階段 昇降を行う。一例として, 義足歩行では, いわゆる伸び あがり歩行のような異常歩行を呈することもあり，切断 側の遊脚期に義足の振り出し時につまずかないように, 非切断側立脚期で非切断側の足関節を底屈させるといっ た代償動作を行う場合がある。ささらは，階段昇降時に も非切断側で義足側を引き上げる際に足関節を底屈させ, 義足側を上段に引き上げることで昇段動作を安全かつス ムースに行っている人も多く存在する。こうした異常歩 行などを呈さない人であっても，下肢切断者は非切断側 に頼って生活している可能性が高く, 下肢切断者では日 常的に非切断側を酷使した行動をとらざるを得ない環境 にあるといえる。こうした日常生活に加え，スポーツを 行うことでより非切断側にかかる負担は増大することが 考えられる。陸上競技ではスポーツ用義足の性能だけで なく, 非切断側で推進力を発生させるために蹴りだしを 力強く行うことが求められる.

健常者では両側の下肢を用いて走行の際に推進力を得 れる一方で, アンプティサッカーなどの立位で行うス ポーツでは, 非切断側への負荷が大きくなることが予想 され, 非切断側には高い機能が求められる ${ }^{2)}$. したがっ て, スポーツを行っている下肢切断者では, 非切断側下 肢への負荷が大きくなり，健常者とは異なる筋収縮特性 を示した要因ではないかと推察した。

さらに，応答スピード $\left(\mathrm{V}_{\mathrm{rn}}\right)$ の結果からも，腓腹筋 内側頭（GM）が下肢切断者で健常者よりも有意に小さ かったことからも，下肢切断者では腓腹筋の筋収縮の反 応に変化が生じることを示唆した。 下肢切断者の非切断 側の筋収縮の特徵として腓腹筋で電気刺激に対する最大 筋膨隆に到達するまでの時間が健常者より遅延すること が示された。

下肢切断者群と健常者群の両群とも外側広筋 (VL) の応答スピード $\left(\mathrm{V}_{\mathrm{rn}}\right)$ が郡内の骨格筋間を比較した時 に他の下肢筋よりも大きいことが示された。 バレーボー ル選手を対象とした先行研究では, 男女ともにVLの応 答スピードが大きいことが述べられており ${ }^{9)}$, 下肢切断 者でも健常者と同様な結果であった，一般的に大腿四頭 筋は Type II 線維が優位な傾向を示すとされ，特に外側 広筋は, 筋横断面積や筋線維総数が他の大腿四頭筋のな かで最も多いといった報告もあり 13)，外側広筋の応答 
スピードが大きかったのではないかと考える．しかしな がら, 本研究からでは, こうした変化が起こった原因や メカニズムについては明らかにすることはできておらず, 今後のさらなる研究が必要である。

スポーツを行ううえで, 競技力向上に向けたより効率 的なトレーニングを行う必要があるが，筋収縮特性を考 慮したトレーニングメニューを構築することが求められ る．健常者に関しては，トレーニングによって TMGの 収縮速度（Tc）や遅延時間（Td）が変化することが示 されており，さらにはトレーニング方法によって筋収縮 特性に与える影響が異なることも報告されている ${ }^{14)}$. したがって, 本研究で得られた結果は, 下肢切断者に対 して効率的なトレーニング方法を考えるために役立つ情 報であるといえる．

本研究の限界は, 対象の年齢が健常者群と下肢切断者 で差が大きかったこととサンプルサイズが小さいことが 挙げられる。年齢の影響について, 20 歳代から 60 歳代 までの健康な人であれば，筋線維タイプに大きな変化は ないとする報告もあり ${ }^{15)}$, 対象とした下肢切断者は切 断以外の疾病のない健康な人であり, 本研究結果に与え た影響については少ない可能性が考えられる。むしろ年 齢の問題より切断からの経過年数によって, 非切断側に 多く依存した生活を長く送っている影響が出ることが考 えられる. 今後はサンプル数を増やしていきさらに下肢 切断者の筋収縮特性について検討していくとともに，年 齢や切断後の経過年数, 競技種目別, 切断部位などの違 いに着目して研究を進める必要がある.

利益相反 本研究に関連し, 開示すべき利益相反関係に ある企業等はない.

\section{引用文献}

1) 陶山哲夫：障害者スポーツの最近の動向. 理学療法科学, 2006, 21: 99-106.

2) Ozkan A, Kayıhan G, Köklü Y, et al.: The relationship between body composition, anaerobic performance and sprint ability of amputee soccer players. J Hum Kinet, 2012, 35: 141-146.

3) Bernardi M, Castellano V, Ferrara MS, et al.: Muscle pain in athletes with locomotor disability. Med Sci Sports Exerc, 2003, 35: 199-206.
4) Rey E, Lago-Peñas C, Lago-Ballesteros J: Tensiomyography of selected lower-limb muscles in professional soccer players. J Electromyogr Kinesiol, 2012, 22: 866-872.

5) Piqueras-Sanchiz F, Martin-Rodriguez $S$, Gonzalez-Hernandez JM, et al.: In-season analysis of the muscle response speed of knee extensors and flexors in elite futsal players. Adv Skeletal Muscle Funct Assess, 2017, 1: 17-22.

6) Rey E, Lago-Peñas C, Lago-Ballesteros J, et al.: The effect of recovery strategies on contractile properties using tensiomyography and perceived muscle soreness in professional soccer players. J Strength Cond Res, 2012, 26: 3081-3088.

7) Martín-Rodríguez S, Loturco I, Hunter AM, et al.: Reliability and measurement error of tensiomyography to assess mechanical muscle function: a systematic review. J Strength Cond Res, 2017, 31: 3524-3536.

8) Valencic V, Knez N: Measuring of skeletal muscles' dynamic properties. Artif Organs, 1997, 21: 240-242.

9) Rodriguez-Ruiz D, Rodriguez-Matoso D, Quiroga ME, et al.: Study of mechanical characteristics of the knee extensor and flexor musculature of volleyball players. Eur J Sport Sci, 2012, 12: 399-407.

10) Maeda N, Urabe Y, Tsutsumi S, et al.: Symmetry tensiomyographic neuromuscular response after chronic anterior cruciate ligament (ACL) reconstruction. Knee Surg Sports Traumatol Arthrosc, 2018, 26: 411-417.

11) Krizaj D, Grabljevec K: Evaluation of muscle dynamic response measured before and after treatment of spastic muscle with a BTX-A: a case study. In: Proceedings of the 11th Mediterranean Conference on Medical and Biological Engineering and Computing, Ljubljana, Slovenia, Volume 16. SpringerInternational Federation for Medical and Biological Engineering, New York, 2007, pp393-396.

12) Loturco I, Gil S, Laurino CF, et al.: Differences in muscle mechanical properties between elite power and endurance athletes: a comparative study. J Strength Cond Res, 2015, 29: 1723-1728.

13) 小林公一：ヒト大腿四頭筋の筋線維構成について．昭和医 学会雑誌, 1997, 51: 186-196.

14) Rusu LD, Cosma GG, Cernaianu SM, et al.: Tensiomyography method used for neuromuscular assessment of muscle training. J Neuroeng Rehabil, 2013, 10: 67.

15) Rodriguez-ruiz D, Garcia-Manso JM, Rodriguez-Matoso D, et al.: Effect of age angphysical activity on response speed in knee flexor and extensor muscles. Eur Rev Aging Phys Act, 2013, 10: 127-132. 